\title{
Correction to: Is Extended-Duration (Post-Hospital Discharge) \\ Venous Thromboembolism Chemoprophylaxis Safe and Efficacious in High-Risk Surgery Patients? A Systematic Review
}

\author{
Saamia Shaikh $^{1} \cdot$ Melanie Reddy $^{1} \cdot$ Mark McKenney $^{1,2} \cdot$ Adel Elkbuli $^{1}$ (D)
}

Published online: 1 July 2020

(C) Société Internationale de Chirurgie 2020

\section{Correction to:}

\section{World J Surg}

https://doi.org/10.1007/s00268-020-05638-4

In the original article, the authors' affiliations and affiliation addresses are inaccurate. They are correct as reflected here.

Publisher's Note Springer Nature remains neutral with regard to jurisdictional claims in published maps and institutional affiliations.

The original article can be found online at https://doi.org/10.1007/ s00268-020-05638-4.

Adel Elkbuli

Adel.Elkbuli@hcahealthcare.com

1 Division of Trauma and Surgical Critical Care, Department of Surgery, Kendall Regional Medical Center, 11750 40th Street, Miami, FL 33175, USA

2 Department of Surgery, University of South Florida, Tampa, FL, USA 